\title{
DESIGN THINKING IN FUTURE TEACHERS TRAINING
}

\author{
Juana M. Ortega-Tudela, Elena M. Diaz-Pareja, África M. Cámara-Estrella, \\ \& Mercedes LLorent-Vaquero \\ Department of Pedagogy, University of Jaén (Spain)
}

\begin{abstract}
Innovation in education entails not only the incorporation of technological tools and applications, but also the implementation of methodologies that could break the inertia and incorporate processes of Divergent Thinking. Future teachers must be creative professionals capable of developing professional activities to improve and not only to replicate the social experience in order to create new learning experiences.

In this way, the main aim of our work was to explore how the use of Design Thinking Methodology improves learning processes in a group of 75 college students of the Primary Education Degree. This group of students, divided into 21 smaller working groups, created different educational videos and multimedia design projects through Design Thinking methodology. They were also encouraged to use Social Networks (specifically Instagram) to present and publicize the progress they were making on their work, in order to obtain feedback from their classmates. All the projects developed were related to three thematic areas: Art for everyone; Attention to diversity and Making great neighborhoods. At the end of the creation process, we analysed the students' perception of how the design thinking methodology helps them through their learning process. Based on an ad hoc questionnaire, the impact of the use of Design Thinking in the learning process and its influence on variables such as motivation, communication, creativity, among others, was studied. The results show that the use of this methodology had a positive impact on practically all the variables, facilitating and optimizing the learning process of future teachers.
\end{abstract}

Keywords: Design thinking, innovation, teachers training, creativity.

\section{Introduction}

Design Thinking is an innovative and creative process centered into students that uses collaborative teams in order to generate the most original solutions. In the past years, wide interest towards Design Thinking has been applied in education because of its ability of advancing creativity and innovation. In addition, Brown (2008) explains that Design Thinking (DT) is a discipline that uses the designer's methods to satisfy the needs of the end-users.

In education, design thinking promotes innovation, problem solving, creativity and collaboration (Anderson, 2012). Rauth, Koppen, Jobst \& Meinel (2010) noted that design thinking allows the participants to work successfully in multidisciplinary teams as they creatively solve difficult real-life problems. Brown (2008) explained that design thinking is seen as a powerful and effective approach to impact innovation that can be integrated in education and other fields. However, what sets design thinking apart from other innovative approaches is that it focuses on the process instead of the product.

Design thinking as a process follows an iterative dynamic process broken down into five specific phases:

Empathize, Define, Ideate, Prototype and Test (Dam \& Siang, 2018).

Empathize is the first stage of the Design thinking process, it is to gain an empathic understanding of the problem we are trying to solve. This first step is crucial to a user-centered design process and allows students to set aside their own assumptions about the problem in order to gain insight into users and their needs.

The second stage is Define. In this step students put together all the information they have gathered during the Empathise stage in order to define the core problems they have identified up to this point.

During the third stage (Ideate) students are ready to start generating ideas, identifying new solutions to the problem defined at the second stage. At the beginning of this phase, it is important to get as many new ideas as possible in order to find the best solution. 
The Prototype stage is an experimental phase and during it, students have to identify the best possible solution for each of the problems. The students implement solutions within prototypes, and all the prototypes must be tried, one by one. At the end of this stage, the students will have a clearer view of how real users would solve the problem using the student's product.

The last phase is Test. During this phase students test the complete product using the best solutions identified during the prototyping phase.

In order to improve future teachers training we have chosen Design Thinking because it could be adapted to any discipline and profession, developing fundamental skills and competencies in today's society. This methodology has been shown to improve teaching-learning experiences and it is beneficial for both teachers and students (Scheer; Noweski \& Meinel, 2012).

\section{Method}

The new educational framework demands the shaping of responsible professionals, committed to their work and willing to transform and improve the reality that surrounds them. In order to institute the changes and innovations that are necessary at the educational and social level, it is imperative for the training of such professionals to be in line with these approaches. Future teachers must be creative professionals capable of developing professional activities to improve and not only to replicate the social experience in order to create new learning experiences. In this way, the main aim of our work was to explore how the use of Design Thinking Methodology improves learning processes in a group of college students of the Primary Education Degree.

\subsection{Sample}

The study was carried out with a sample composed of a total of 65 participants aged between 19-28 years $(\mathrm{M}=20.16, \mathrm{SD}=1.51)$, all of whom were students at the University of Jaén (Spain). The participants belonged to the second year of the Degree in Elementary Education. This group of students, divided into 21 smaller working groups, created different educational videos and multimedia design projects through Design Thinking methodology. The students were participating in the subject New Technologies applied to Education. The practical curricular placements for the subject were carried out in accordance with the DT methodology, such that students designed and carried out, in collaboration with the teachers involved, small design-thinking projects that responded to the needs observed in their social environment. These practical placements were undertaken in small groups (4-6 students) and followed the fundamental scheme and the defining principles of this methodology. They were also encouraged to use Social Networks (specifically Instagram) to present and publicize the progress they were making on their work, in order to obtain feedback from their classmates. All the projects developed were related to three thematic areas: Art for everyone; Attention to diversity and Making great neighborhoods.

At the end of the creation process, we analyzed the students' perception of how the design thinking methodology helps them through their learning process.

\subsection{Instrument}

An ad hoc questionnaire was designed in order to analyze the impact that the use of the Design Thinking methodology and the use of Instagram in the learning process and its influence on different variables was studied. The questionnaire was composed by 38 items divided into nine dimensions:

a) Identification items; Items related to the personal data as gender, age, ...

b) Motivation; items focused on analyzing the student's motivation during the process.

c) Involvement to connect to class; to participate in, to achieve learning...

d)Creativity; searching for sources of inspiration; searching for different answers; ...

e)Communication; Between class groups; between group members; between groups and teachers; quantity; quality; fluency....

f) Supervise; accompaniment; feedback; teacher guidance; supervision; support.

g)Publish; Publicizing results; publicizing their work;...

h)Success; motivation towards success; Perception of usefulness of work...

i) Social Implication: To awaken interest in the service; to encourage participation in other social actions.

The questionnaire was validated through expert judgement. Lawshe content validity index was used to measure strength of agreement $(\mathrm{CVI}=.966)$ (Ayre \& Scally, 2014). A Likert scale with five-point agreement was used to measure students' agreement (being $0=$ completely disagree to $5=$ completely agree). 


\section{Results}

The students score all the variables above 3.5 (see figure 1). For the dimension of Motivation all the items scored above 3,6.

Figure 1. Mean Averages for variable.

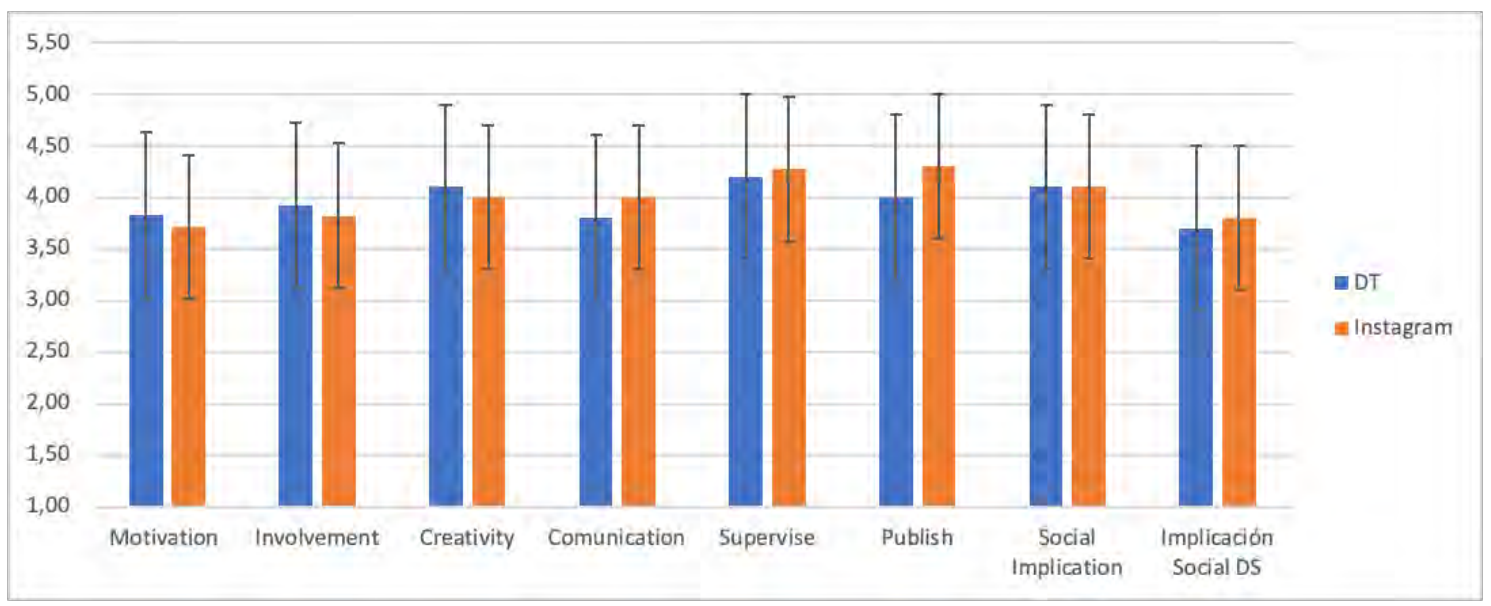

Some of the most significant results could be observed when analyzing the percentages achieved in some of the items that compose the dimensions. Almost all students agree with the statement that Instagram and DT are increasing their motivation for the project.

Figure 2. Percentages for the item "increased your motivation for the project".

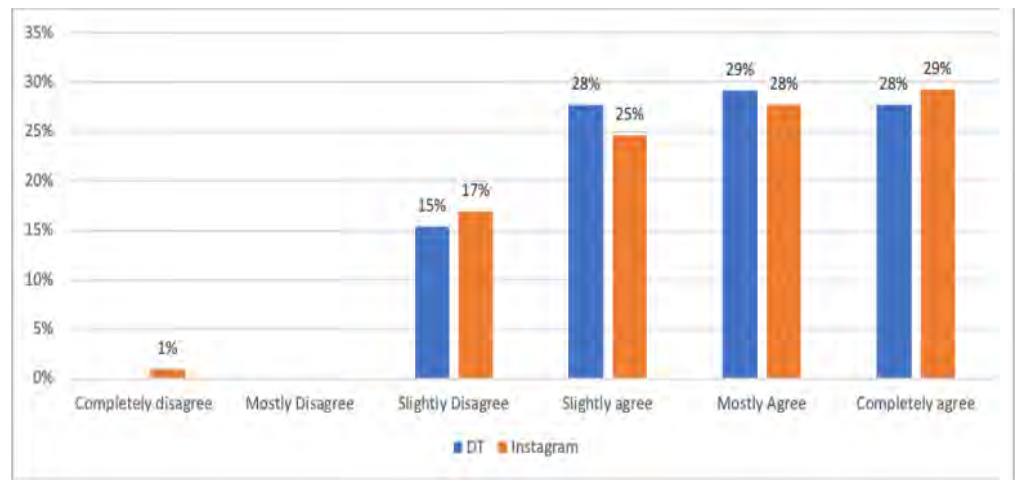

Asked about effort, most of the students strongly or completely agree that both methodologies increased their level of effort towards the project (see Figure 3). The same level of agreement could be observed with the statement about the level of creativity (see Figure 4)

Figure 3. Percentages for the item "increased your effort".

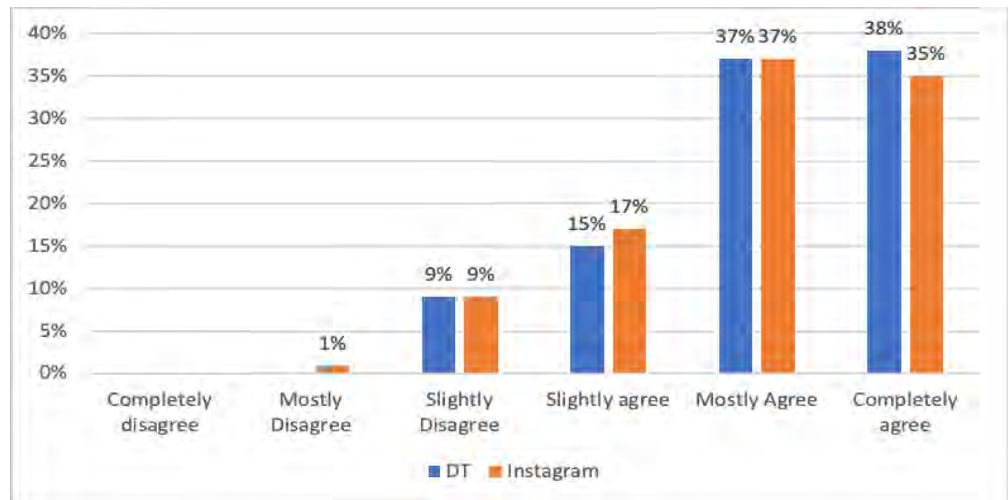


Figure 4. Percentages for the item "increased your creativity".

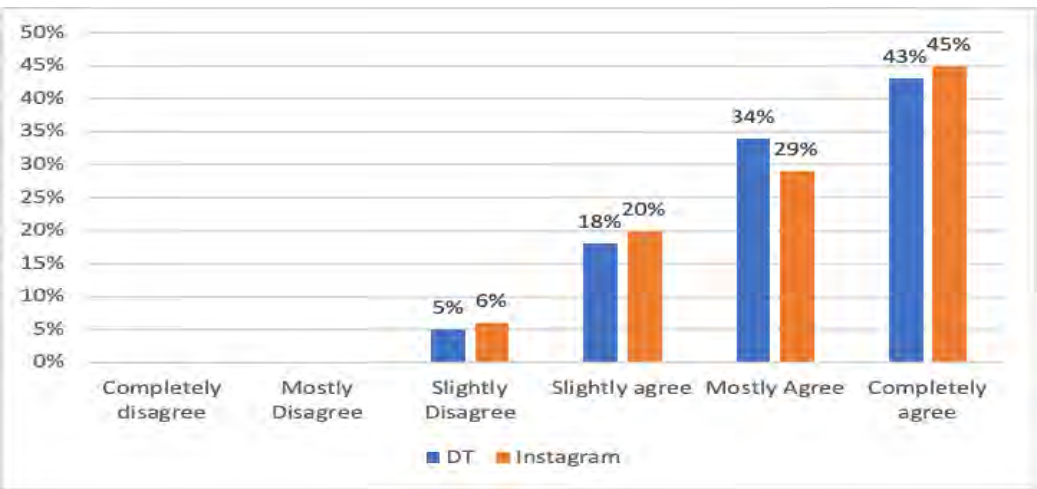

Regarding the variable communication most of the students consider that they have improved their communication with the teacher (see Figure 5). In addition, among all of them, consider that the use of those methodologies has favoured the teacher's monitoring of their progress in the project (see Figure 6).

Figure 5. Percentages for the item "Improved your communication with the teacher".

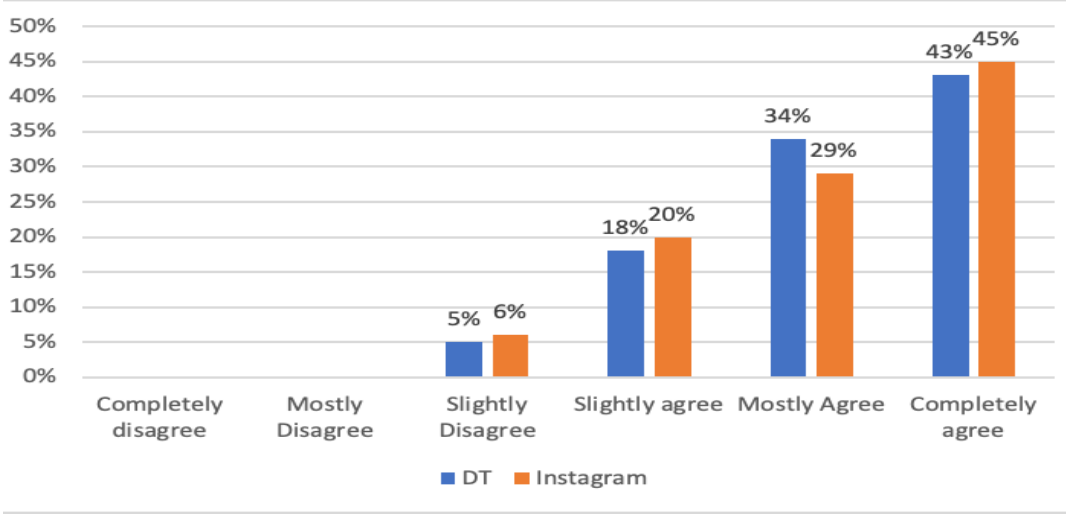

Figure 6. Percentages for the item "Favored the teacher's monitoring".

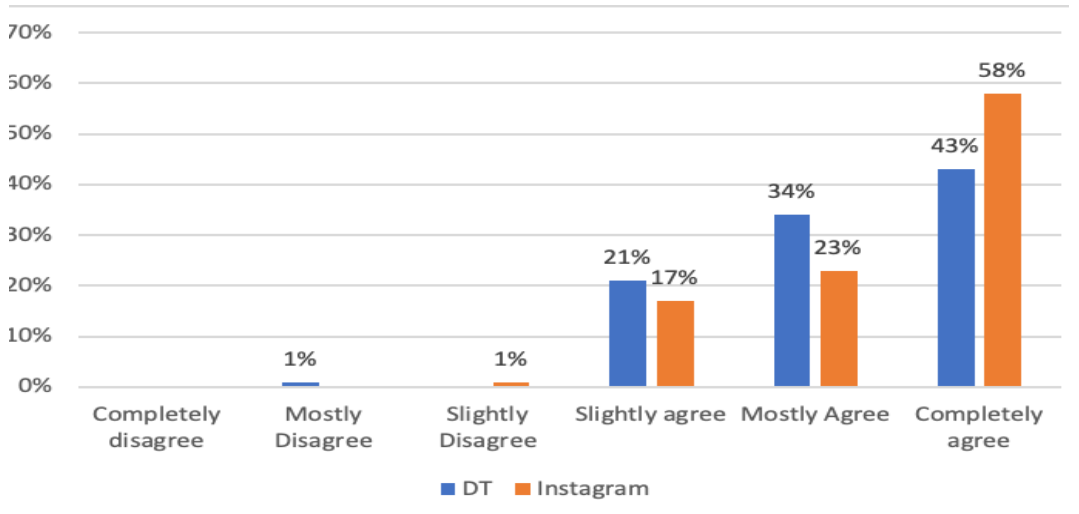

\section{Conclusions}

In recent years, DT has been configured as a novel and creative strategy to address problem solving that can be applied to a multitude of fields and disciplines (Dorst, 2011). Design thinking is a teamwork method that encourages student participation, creative thinking and improves their learning experiences 
(Bongiovanni \& Balgabekova, 2021). In addition, Design thinking helps students to contextualize needs, generate useful solutions and develop empathy, since it is part of human-centered design.

In our study, the results show that the use of this methodology had a positive impact on practically all the variables, facilitating and optimizing the learning process of future teachers. Students have improved not only in creativity and metacognition, but communication with teachers has increased, being one of the variables that we highlight as very positive. In addition, we agree with Scheer, Noweski \& Meinel (2012) that it is necessary for teachers to be trained in this technique and gain confidence in its use, so we think it would be necessary to include it in the training of future teachers.

\section{References}

Anderson, N. (2012). Design Thinking: Employing an Effective Multidisciplinary Pedagogical Framework to Foster Creativity and Innovation in Rural and Remote Education. Australian \& International Journal of Rural Education, 22(2), 43-52. Retrieved from http://search.ebscohost.com/login.aspx?direct=true\&db=ehh\&AN=80037529\&site=ehostlive

Ayre, C., \& Scally, A. J. (2014). Critical values for Lawshe's content validity ratio: revisiting the original methods of calculation. Measurement and Evaluation in Counseling and Development, 47(1), 79-86. https://doi.org/10.1177/0748175613513808

Bongiovanni, I., \& Balgabekova, D. (2021). Ask me if I am Engaged: A Design-led Approach to Collect Student Feedback on their University Experience. Design and Technology Education: An International Journal, 26(1), 89-117. Retrieved from: https://ojs.lboro.ac.uk/ DATE/article/view/2864

Brown, T. (2008). Design Thinking. Harvard Business Review, 1-10.

Dam, R. \& Siang, T. (2018). 5 stages in the design thinking process. Retrieved from https://www.interaction-design.org/literature/article/5-stages-in-the-design-thinking-process

Dorst, K. (2011). The core of 'design thinking' and its application. Design Studies, 32, pp. 521-532. doi:10.1016/j.destud.2011.07.006

Rauth, I., Köppen, E., Jobst, B., \& Meinel, C. (2010). Design Thinking: An Educational Model towards Creative Confidence. In First International Conference on Design Creativity (pp. 1-8). Kobe, Japan.

Scheer, A.; Noweski, C. \& Meinel, C. (2012). Transforming Constructivist Learning into Action: Design Thinking in education. Design and Technology Education: An International Journal, 17 (3), pp. 8-19. Retrieved from: https://ojs.lboro.ac.uk/DATE/article/view/1758 